\title{
Shroom: A Cultural History of the Magic Mushroom
}

Andy Letcher. 2007. Ecco HarperCollins, New York. Pp. 384. \$14.99 (paperback). ISBN 9780060828295.

\author{
Reviewed by Sveta Yamin-Pasternak ${ }^{1}$ \\ Reviewer Address: ${ }^{1}$ University of Alaska Fairbanks, Fairbanks, Alaska 99775
}

Received: July $30^{\text {th }} 2009$

Volume 1:26-27

Published: August $25^{\text {th }} 2010$

(C) 2010 Society of Ethnobiology

"We could claim living in the Mushroom Age. We are the mushroom people" (p.5), is how Andy Letcher begins his grand historico-biographical odyssey. Letcher's "we" is a stratum of post World War II generations, whose experience of coming of age dwells within the contours of a certain transnational culture. This culture thrives on its enchantment with the magic mushroom, drawing fulfillment and inspiration from the mushroom's pharmacological qualities and historical roles, both real and imagined. "We" were the (re)discoverers, the pioneers, and the recipients of the psychedelic research, revolution, and substances. "We" are the ones who sought McKenna's true hallucinations and Castaneda's journeys. Collectively, we share a need to feel that our individual corporal way of being in the world transcends into alternate universes, inhabited by wisdoms of the ancients. The prominence we ascribe to the role of the magic mushroom in human prehistory is a reflection of that need, as is the eagerness with which we embrace it. The urge to connect our past to the use of the magic mushroom says more about us, here and now, than it does about anything in our past. That is the overreaching argument of the vast, enticing, and masterful treatise Shroom: A Cultural History of the Magic Mushroom.

The book is organized into three main parts, each carrying a title of a mycological category: Agaricus (I), Amanita (II), and Psilocybe (III). The first of the trilogy provides an overview of mushroom anatomy, ecology, and chemistry. It also explains how the compounds found in particular species interact with the human body to produce a psychoactive effect. Following the mycology fundamentals, Letcher unveils a compilation of fables, which ascribe the genesis and the essence of human religious thought to the use of the magic mushroom. Through the efforts of a diverse cast of characters - writers, scholars, businesspeople, artists, and charismatic teachers - the hypotheses connecting "shrooming" with early enlightenment had anchored firmly in the historiography of the magic mushroom. Legitimized, in part by academic research and discussion, during the rise of the Mushroom Age the stories that Letcher calls "tripper's tales" have attained the level of scripture. One by one, Letcher deconstructs these pillars of the mushroom mythology that are likely to ring familiar to the readers of Ethnobiology Letters, such as the supposed shamanic origin of the Santa Claus figure, or the deciphered mushroom identity of the sacred Soma plant in the Vedic hymns. The cultural context that enabled the propagation and widespread acceptance of the Mushroom Age mythology is, to a great extent, what makes "the real and as yet untold history [of the magic mushroom] at once less fanciful and far more interesting" (p. 5).

With the mirror facing contemporary Western society, positioned at such a revealing vantage point, and interpreted in Letcher's edge-of-the-seat style of narration, this cultural critique should appeal to broad audiences. Readers with a special affinity for mushrooms are bound to marvel at the multiple twists and turns of the plot, unraveling some long overlooked mysteries and presenting familiar controversies in a different light. The book is packed with biographical gems about the lives of prominent contributors to the study of human relationships with fungi, including Gordon Wasson, Mordechai Cubitt Cooke, Stephen Hayden Pollock, and many others. For practitioners of ethnobiology, Shroom is an opportunity to reflect on how a scholarly exploration of a life form can boost its general popularity and shape its public perception.

Within the range of existing theories that Letcher sets out to debunk, the idea of mycophilic and mycophobic cultures, once proposed by Valentina and Gordon Wasson, comes under a particularly strong disparagement. Inspired by the polarity of their own attitudes (Russian by birth, Valentina adored mushrooms while her American Anglo-Saxon husband, Gordon, regarded them with abhorrence and fear), the 
Wassons carried out a broad ethnological survey, finding that a number of other world populations show a strong emotion toward mushrooms. The disposition of a culture where mushrooms are valued and widely consumed, such as the kind found throughout Eastern Europe, the Wassons had labeled as "mycophilia." The condition of overwhelming disdain for mushrooms, on the other hand, which at the time of their writing was true for Britain, became known as that of "mycophobia." Letcher finds the dichotomy problematic. "The term "phobia," he says, "implies an overwhelming and irrational panic reaction..., whereas anxieties about mushrooms are wholly rational. In the absence of any reliable methods for distinguishing the edible from the poisonous..., blanket avoidance of all mushrooms is the most sensible and reasonable option” (p. 95).

Although the logic of the last argument may appear sensible to a person who did not grow up eating wild mushrooms, for a person from Belarus it sounds just as unreasonable as would, in our day and age, an agitation to stay away from cars and airplanes for the fear of a possible crash. Perhaps it is no accident that the author of Shroom himself happens to be from the UK? The fact that his perspective aligns so flawlessly with the one ascribed to the British culture as a whole, and the type I encounter frequently in the United States, suggests that the attempted counterevidence actually speaks in support of the hypothesis it tries so hard to dispute. This leaves us with plenty of reassurance that the story of fungi and humanity is to be continued. 